\title{
Risks Analysis of Logistics Financial Business Based on Evidential Bayesian Network
}

\author{
Ying Yan $^{1}$ and Bin Suo \\ ${ }^{1}$ School of Economics and Business Administration, Southwest University of Science and Technology, Mianyang 621010, China \\ ${ }^{2}$ Institute of Electronic Engineering, China Academy of Engineering Physics, Mianyang 621900, China \\ Correspondence should be addressed to Ying Yan; yanying_527@163.com
}

Received 19 February 2013; Revised 13 June 2013; Accepted 2 July 2013

Academic Editor: Yingwei Zhang

Copyright (c) 2013 Y. Yan and B. Suo. This is an open access article distributed under the Creative Commons Attribution License, which permits unrestricted use, distribution, and reproduction in any medium, provided the original work is properly cited.

\begin{abstract}
Risks in logistics financial business are identified and classified. Making the failure of the business as the root node, a Bayesian network is constructed to measure the risk levels in the business. Three importance indexes are calculated to find the most important risks in the business. And more, considering the epistemic uncertainties in the risks, evidence theory associate with Bayesian network is used as an evidential network in the risk analysis of logistics finance. To find how much uncertainty in root node is produced by each risk, a new index, epistemic importance, is defined. Numerical examples show that the proposed methods could provide a lot of useful information. With the information, effective approaches could be found to control and avoid these sensitive risks, thus keep logistics financial business working more reliable. The proposed method also gives a quantitative measure of risk levels in logistics financial business, which provides guidance for the selection of financing solutions.
\end{abstract}

\section{Introduction}

Logistics finance is a new business for financing, in which participants are bank, small and medium enterprise, and third part logistics enterprise (3PL). In this business, bank is the one to offer the funds, small and medium enterprise is the ones which need the funds, and 3PL plays the supervision role.

In logistics financial business, the variation of operational mode leads to fundamental changes in lending risks. The participants turn from two into three, the financing mode is more flexible, and the contract is more complex. So the traditional measures of financial risk assessment have been unable to meet the requirements of the logistics financial business.

To motivate the healthy development of the logistics financial business, many domestic and overseas scholars focused on the research of risk identification, evaluation, and prevention in the business. For example, Jokivuolle et al. [1] studied the safe loan-to-value ratio for bank when the default risk was endogenous for capital demander. Buzacott et al. [2] studied the effects of inventory management, interest, and loan amount limitation on risk control. Jia et al. [3] studied the risk evaluation in logistics finance business in the view of logistics enterprise. Cossin et al. [4] constructed a general framework for risk control of collateral security and analyzed the impacts of mark-to-market frequency, interest rate volatility, and liquidity risk on discount rate. Rajan et al. [5] considered that the number of collateral security was positively correlated with the size of the payment risk. Chen et al. [6] proposed a model to assess risk level of the value in inventory financing business, and found the most sensitive risk factors by sensitivity analysis. Under the assumption that the realizable value was subjected to the geometric Brownian motion, Chang et al. [7] constructed an evaluation model for liquidity risk based on L-VaR method, which could make a judgment whether the circulation attribute of the collateral security could meet the requirements of the pledge.

Logistics finance is a complex business, in which there are three sources of risks coming from the three bodies, that is, financing enterprise, logistics enterprise, and bank. These risks may lead to the default of one of the three bodies and even the termination of the whole business. However, from foregone literatures about logistics finance, researches on risk 
assessment and control were mainly from the perspective of bank and did not consider the problem from the point of view of all the participants in the business. And more, it is critically important to know the magnitude of failure probability about the logistics financial business, and which risk is more sensitive than others. Relevant reports about those were also not seen at home and abroad.

The motivation of this research work is to measure the sensitivities of different risks on logistics financial business and quantitatively get the amount of risk of the whole business. Bayesian network is introduced to construct a risk assessment network. Considering that the probability of occurrence of each risk factor could not be estimated exactly on many occasions, evidence theory is used to combine the correlative information, and an evidential Bayesian network is constructed for further analysis.

\section{Logistics Financial Business}

The operation patterns of logistics business include warehouse receipt pledge [8], inventory impawn [9], financing storehouse [10], accounts receivable financing [11], confirming storage [12], and so on. The essence of the first three is taking the ownership of the merchandise as guarantee of movable property. Warehouse receipt pledge and inventory impawn are both static financing businesses, while financing storehouse is a dynamic one, in which loading/unloading transaction can be made freely by keeping a certain amount of pledges. Accounts receivable financing business includes two modes, logistic factoring, and accounts receivable pledge. Confirming storage is a business of finance in upstream supply chain, and its characteristic is starting shipping after receiving the receipt.

The enterprise which does warehouse receipt pledge, inventory impawn, or financing storehouse normally lies in the downstream of the core enterprise in supply chain and purchases from the core enterprise. The enterprise which does accounts receivable financing lies in the upstream of the core enterprise in supply chain and supplies the core enterprise. In confirming storage business, after getting the receipt, it transforms to a warehouse receipt pledge business [2].

According to the modes of aforementioned businesses, the financing direction, means of credit, and properties of credit are summarized in Table 1.

\section{Risk Identification of Logistics Financial Business}

The sources of risks in logistics financial business include credit, morality, legal, and management.

Credit risks are that the counterparty fails to fulfill the contract and spawns a great number of economic losses. Default risks, market risks, and earnings risks are all belonging to this type of risks. Default risks are that the contract cannot be fulfilled because of force majeure. If there are large price fluctuations in the market, then contradiction may occur between financial provider and demander, and one or both sides may withdraw the financing business. This phenomenon is so-called market risks. If financing costs exceed the expectations of finance enterprise, it may exit the business. Otherwise, if the financing incomes are lower than the expectation of the bank, it may withdraw the business. Earnings risks mean finance enterprise exiting the business when the profits cannot cover the finance costs because of their awful management conditions.

Moral risks come from the malicious fraud of finance enterprise. In logistics business, 3PL may help finance enterprise to swindle the wealth by providing false information to bank.

Legal risks are mainly the following aspects. First, some laws in logistics finance terms are not clear and perfect. Second, there may have been illegality clauses in financing agreements. Third, the ownership of the pledge provided by finance enterprise may be disputed. Last, validity of pledges is doubted in some time. For example, smuggled goods are illegal. In addition, as the business involves advantages of many main bodies, the ownership of pledges is translated from one to the others, so the ownership disputes may occur.

Management risks often come from logistics enterprise and finance enterprise, respectively. Management risks in finance enterprise are produced when managers make inaccurate decisions or staffs operate error. The accuracy of the evaluation of pledges is very important, which directly affects the efficiency of logistics finance. Management risks in logistic enterprise are caused by inaccurate decisions, imperfect management system, and incorrect pledge management. The management risks of pledges for logistics enterprise are divided into the following aspects. First, the insurance of pledges is unregulated. Second, selection of pledges is improper. Third, there are quality defects in pledges. Last, the regulating system of pledges is imperfect.

Taken as a whole, the risks in logistics finance are summarized in Table 2.

\section{Risks Analysis for Logistics Financial Business Using Bayesian Network}

Risks in logistics finance may lead the failure of the business. In order to quantitatively analyze the impact on logistics finance with these risks, Bayesian network conjunction with evidence theory is used in this section.

The reasoning mechanism and the description of fault status in Bayesian network are very similar as those in fault tree. However, Bayesian network has many advantages when compared with fault tree in some situations. For example, in the description for nondeterministic logic and polymorphism and adding some new events to a prebuilt fault tree, Bayesian network is more effective than fault tree.

The basic concepts and theorems are introduced first, and then the risk analysis of logistics financial business is conducted.

4.1. Bayesian Network. Bayesian network is a directed acyclic graph, which is a powerful tool of uncertainty describing and propagating [13]. A Bayesian network with $m$ nodes is 
TABLE 1: Classification of logistics financial businesses.

\begin{tabular}{|c|c|c|c|c|c|}
\hline \multirow[b]{2}{*}{ Property } & \multicolumn{5}{|c|}{ Mode } \\
\hline & $\begin{array}{l}\text { Warehouse receipt } \\
\text { pledge }\end{array}$ & $\begin{array}{l}\text { Inventory } \\
\text { impawn }\end{array}$ & $\begin{array}{l}\text { Financing } \\
\text { storehouse }\end{array}$ & $\begin{array}{l}\text { Accounts } \\
\text { receivable } \\
\text { financing }\end{array}$ & $\begin{array}{l}\text { Confirming } \\
\text { storage }\end{array}$ \\
\hline $\begin{array}{l}\text { Relative position of finance enterprise } \\
\text { in supply chain }\end{array}$ & Downstream & Downstream & Downstream & Anywhere & Downstream \\
\hline Direction of financing in supply chain & Upstream & Upstream & Upstream & Downstream & Upstream \\
\hline The pledge & Warehouse receipt & Inventory & Inventory & Obligatory right & Goods to buy \\
\hline Means of credit & Ownership & Ownership & Ownership & Obligatory right & Buyer's credit \\
\hline Properties of credit & $\begin{array}{l}\text { Drawn right of } \\
\text { movables for pledge }\end{array}$ & $\begin{array}{l}\text { Movables for } \\
\text { pledge }\end{array}$ & $\begin{array}{l}\text { Movables for } \\
\text { pledge }\end{array}$ & $\begin{array}{l}\text { Movables for } \\
\text { pledge }\end{array}$ & Prepayment \\
\hline
\end{tabular}

TABLE 2: Risks in logistics finance.

\begin{tabular}{|c|c|c|c|c|}
\hline \multirow{2}{*}{ Source } & \multicolumn{4}{|c|}{ Risk type } \\
\hline & Credit risks & Management risks & Legal risks & Morality risks \\
\hline $\begin{array}{l}\text { Logistics } \\
\text { enterprise }\end{array}$ & - & $\begin{array}{c}\text { Inaccurate decisions, imperfect } \\
\text { management system, and incorrect } \\
\text { pledge management }\end{array}$ & - & $\begin{array}{l}\text { Malicious cheating of } \\
\text { insiders }\end{array}$ \\
\hline $\begin{array}{l}\text { Finance } \\
\text { enterprise }\end{array}$ & Profits lower than costs & Inaccurate decisions, staff to operate error & - & Malicious fraud \\
\hline Pledge & - & $\begin{array}{l}\text { Incorrect selection of pledges, quality } \\
\text { defects in pledges, and imperfect } \\
\text { regulating system for pledges }\end{array}$ & $\begin{array}{l}\text { Validity of pledges, } \\
\text { ownership disputes }\end{array}$ & - \\
\hline The others & $\begin{array}{c}\text { Force majeure, } \\
\text { fluctuations in } \\
\text { financing service price }\end{array}$ & $\begin{array}{l}\text { Safety management, constructing of } \\
\text { consummate regulating system }\end{array}$ & $\begin{array}{l}\text { Illegality clauses in } \\
\text { financing agreement, no } \\
\text { corresponding laws to } \\
\text { support the agreement }\end{array}$ & $\begin{array}{l}\text { Low credit of operators, } \\
\text { malicious fraud }\end{array}$ \\
\hline
\end{tabular}

expressed as $G=((N, A), D)$, where $(N, A)$ is a directed acyclic graph; $N$ is the set of the nodes, that is, $N=$ $\left\{N_{1}, N_{2}, \ldots, N_{m}\right\} ; A$ is the set of directed arcs between any two nodes, which shows the correlation of the variables; $D$ presents the conditional probability distribution associated with each node. The set of parent nodes of $N_{i}$ is expressed as $\operatorname{Pa}\left(N_{i}\right)$. Each node meets the independence condition of Markov:

$$
p\left(N_{i} \mid N_{1}, N_{2}, \ldots, N_{i-1}, \zeta\right)=p\left(N_{i} \mid \operatorname{Pa}\left(N_{i}\right), \zeta\right) .
$$

The condition probability formula is

$$
P(\mathrm{~A} \mid B)=\frac{P(B \mid \mathrm{A}) P(A)}{P(B)},
$$

where $P(B)$ is prior probability, $P(A \mid B)$ is posteriori probability, and $P(B \mid A)$ is likelihood probability.

If $A$ denotes a variable with $n$ statuses, $a_{1}, a_{2}, \ldots, a_{n}$, then, from complete probability formula,

$$
P(B)=\sum P\left(B \mid A=a_{i}\right) P\left(A=a_{i}\right) .
$$

By equations (2) and (3), the posteriori probability, $P(\mathrm{~A} \mid B)$, can be calculated. Bayesian network can be used for bidirectional reasoning. That is, not only getting prior probability from posteriori probability, that is, obtaining results from reasons, but also getting posteriori probability from prior probability, that is, obtaining reasons from results. These features make it widely used in reliability analysis [14], fault diagnose [15], risk analysis [16], and so on.

4.2. Risk Analysis of Logistics Financial Business. Unlike in $[17,18]$, risks in logistics financial business are all qualitative, and there are no explicit risk-detection thresholds. So the most important work is finding the most critical risks so as to enact measures to control them. To determine the magnitude of the risks in logistics financial business and the sensitivity of each risk to the failure of the business, a Bayesian network is constructed with MSBNx [19]. In the network, the root node is "failure of the logistics finance", and the leaf nodes are the risks in the business, as shown in Figure 1. Leaf nodes in the Bayesian network are described in Table 3.

In Table 3, the 8 th to 12 th and 14 th to 17 th risks could be detected and isolated at any time in the process of logistics financial business. The first five risks could not be detected and removed in the process of logistics financial business because all of these risks are introduced by market, and none of any part in the business could forecast and control them. The rest of the risks are hard to be detected because they are determined by professional qualities. But there are some strategies that can help enterprises to control these risks. For example, the contract of logistics financial business can set 


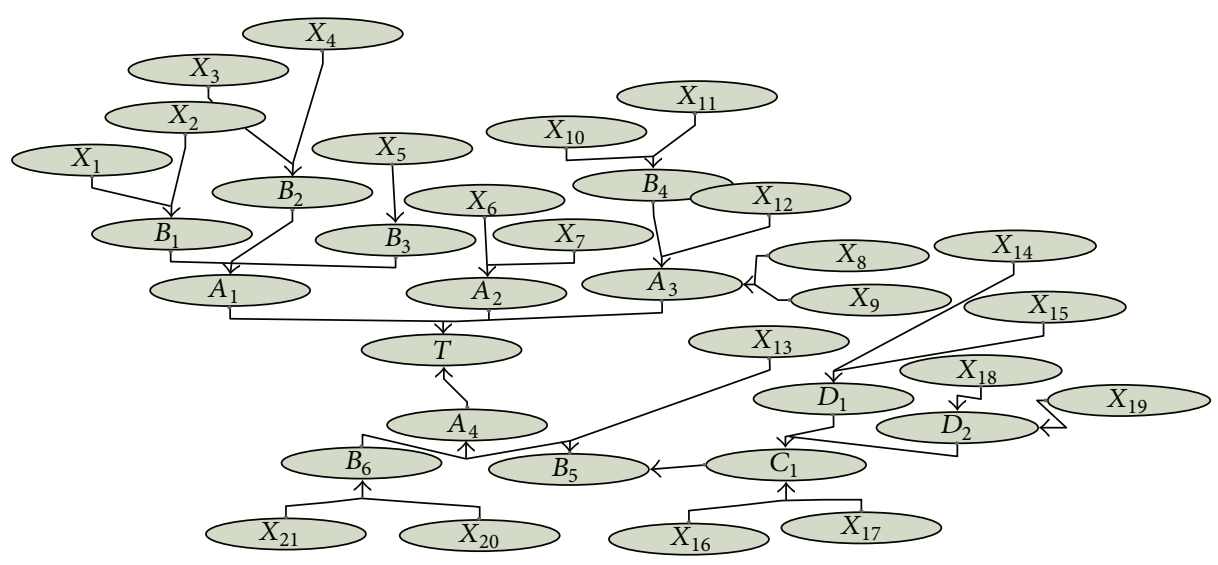

FIgURE 1: Bayesian network of logistics financial business.

TABLE 3: Leaf nodes in the Bayesian network.

\begin{tabular}{ll}
\hline Leaf node & Description \\
\hline$X_{1}$ & Default of finance enterprise caused by force majeure \\
$X_{2}$ & Default of supplier caused by force majeure \\
$X_{3}$ & Exiting of finance enterprise caused by funding costs \\
$X_{4}$ & rising \\
$X_{5}$ & Exiting of bank caused by funding incomes dropping \\
$X_{6}$ & The costs beyonding the profits for finance \\
$X_{7}$ & Malicious falsehood of finance enterprise \\
$X_{8}$ & Malicious cheating of insiders \\
$X_{9}$ & Illegality clauses in financing agreement \\
$X_{10}$ & Ownership of the pledges is disputed \\
& No corresponding laws to support the logistics \\
$X_{11}$ & finance agreement \\
$X_{12}$ & Comprehension rifts in contract for three main \\
$X_{13}$ & bodies \\
$X_{14}$ & Validity of pledges \\
$X_{15}$ & Incorrect decisions of 3PL \\
$X_{16}$ & Deteriorations in pledges \\
$X_{17}$ & Incorrect selection of pledges \\
$X_{18}$ & Mass defects in pledges \\
$X_{19}$ & Improper delivery of pledges \\
$X_{20}$ & Poor regulation for pledges \\
$X_{21}$ & Incorrect decisions of finance enterprise \\
\hline & Staff of finance enterprise to operate error \\
\hline
\end{tabular}

a clause to deal with the problem that the ownership of the pledges is disputed.

As there is conditional independence in the nodes of Bayesian network, the disjoint algorithm and calculation of minimum path and cut set are not needed [20]. Probability of root node $(T)$ is calculated directly by joint probability distribution as

$$
P(T=1)=\sum_{X_{1}, \ldots, X_{n-1}} P\left(X_{1}=s_{1}, \ldots, X_{n-1}=s_{n-1}, T=1\right),
$$

where $s_{i} \in\{0,1\}$ represents whether $X_{i}$ occurs and $n$ represents the number of nodes in the Bayesian network.

The three importance indexes can easily be calculated by graph reduction, clique tree propagation, bucket elimination, or the other algorithms [20].

Probabilistic importance index is

$$
I_{i}^{\mathrm{Pr}}=P\left(T=1 \mid E_{i}=1\right)-P\left(T=1 \mid E_{i}=0\right) .
$$

Structural importance index is

$$
\begin{array}{r}
I_{i}^{\mathrm{St}}=P\left(T=1 \mid E_{i}=1, P\left(E_{j}=1\right)=0.5\right) \\
-P\left(T=1 \mid E_{i}=0, P\left(E_{j}=1\right)=0.5\right), \\
1 \leq j \neq i \leq N .
\end{array}
$$

Critical importance index is

$$
\begin{aligned}
I_{i}^{\mathrm{Cr}} & =\frac{P\left(E_{i}=1\right)\left(P\left(T=1 \mid E_{i}=1\right)-P\left(T=1 \mid E_{i}=0\right)\right)}{P(T=1)} \\
& =\frac{P\left(E_{i}=1\right)}{P(T=1)} I_{i}^{\mathrm{Pr}} .
\end{aligned}
$$

By calculating the importance indexes, important risks can be found. With these information, effective measures can be done to control the risks, thus keep logistics financial business working more reliable.

4.3. Risk Analysis of Logistics Financial Business with Epistemic Uncertainties. In practice, occurrence probabilities of risks are hard to be determined accurately. The probability of a risk may be not a fixed value but an interval, which includes epistemic uncertainties. Bayesian network is unable to handle epistemic uncertainties, so in this section evidence theory is in conjunction with it to handle them.

In the following, basic definitions and theorems of evidence theory associated with this paper will be introduced. More detailed contents can be found in [21-23].

For a given evidential event $A$, basic probability assignment (BPA) is represented by $m(A)$, which defines a mapping 
of the power set to the interval between 0 and 1 , that is, $m: 2^{\Theta} \rightarrow[0,1]$, where $2^{\Theta}$ is the power set of frame of discernment $\Theta$. The value of BBA for $A$ (represented as $m(A)$ ) expresses the proportion of all relevant and available evidence that supports the claim that a particular element of $\Theta$ belongs to the set $A$ and has no additional claims about any subsets of $A$ [22]. The value of $m(A)$ belongs only to the set $A$ and makes no additional claim about any subsets of $A$. For example, if $B \subset A$, then $m(B)$ is another BBA. Generally, $m(A)$ must satisfy the following axioms:

$$
\begin{aligned}
& m(A) \geq 0, \quad \forall A \in 2^{\Theta}, \\
& m(\varnothing)=0, \\
& \sum_{A \subseteq 2^{\Theta}} m(A)=1 .
\end{aligned}
$$

If $m$ is a BBA on $\Theta$, then function Bel : $2^{\Theta} \rightarrow[0,1]$ defined by

$$
\operatorname{Bel}(A)=\sum_{B \subseteq A} m(B)
$$

is a belief function, and function $\mathrm{Pl}: 2^{\Theta} \rightarrow[0,1]$ defined by

$$
\operatorname{Pl}(A)=\sum_{B \cap A \neq \varnothing} m(B)
$$

is a plausibility function, where $A \in 2^{\Theta}$ and $A \neq \varnothing$.

These two functions can be derived from each other. For example, belief function can be derived from plausibility function in the following way:

$$
\operatorname{Bel}(A)=1-\operatorname{Pl}(\bar{A}) \text {. }
$$

The relationship between belief and plausibility function is

$$
\operatorname{Bel}(A) \leq \operatorname{Pl}(A)
$$

Equation (4) shows that as a measure of "event $A$ is true". If $P(A)$ is the true value of the measure of set $\{A$ is true $\}$, then $\mathrm{Pl}(A)$ is a the upper bound of $P(A)$, and $\operatorname{Bel}(A)$ is the lower bound. So

$$
\operatorname{Bel}(A) \leq P(A) \leq \operatorname{Pl}(A)
$$

Let $m_{1}, m_{2}, \ldots, m_{n}$ be the BBAs on $\Theta$, and the focal elements are $A_{i}(i=1,2, \ldots, n)$, then

$$
m(A)= \begin{cases}\frac{1}{1-K} \sum_{\cap A_{i}=A} \prod_{1 \leq i \leq n} m_{i}\left(A_{i}\right) & A \neq \varnothing \\ 0 & A=\varnothing,\end{cases}
$$

where $K=\sum_{\cap A_{i}=\varnothing} \prod_{1 \leq i \leq n} m_{i}\left(A_{i}\right)$.

Equation (6) is the Dempster's rule of mult-sources information combination.

When there are epistemic uncertainties in the nodes, uncertainties is propagated from bottom events to root node by evidential network.
Let $X=1$ express the risk $X$ occur and $X=0$ express the risk $X$ not occur. Then the discernment of frame is $\Omega=\{0,1\}$. If $m: 2^{\Omega} \rightarrow[0,1]$ is the basic probability assignment, then its power set is

$$
\begin{array}{r}
2^{\Omega}=\{m(E=\varnothing)=0 ; m(E=\{1\}) ; \\
m(E=\{0\}) ; m(E=\{0,1\})\} .
\end{array}
$$

The focal element $\{0,1\}$ expresses the unknown state about whether the risk is occurring or not.

As shown in Figure 2, there are epistemic uncertainties in nodes $X_{i}$ and $X_{j}$. Then the probability of intermediate node, $M$, is not a fixed value but an interval as well. The lower and upper bounds are measured by $\operatorname{Pl}(M=1)$ and $\operatorname{Bel}(M=1)$ in evidence theory, respectively. The true value $P(M=1)$ is within the interval, that is,

$$
\operatorname{Bel}(M=1) \leq P(M=1) \leq \operatorname{Pl}(M=1) .
$$

The status of $M$ is represented by conditional probability, as shown in Table 4. If " 1 " denotes the event occurring, " 0 " denotes not occurring, and "0_1" denotes a fuzzy status, then $\operatorname{Bel}(M=1)$ and $\operatorname{Pl}(M=1)$ are obtained by (5) and (6), as shown in Table 4.

With Table 4, Figure 2, and (4), the belief probability of root node, $\operatorname{Bel}(T=1)$, and plausibility probability of root node, $\mathrm{Pl}(T=1)$, are calculated by evidential network propagating. The actual occurrence probability of root node meets $P(T=1) \in[\operatorname{Bel}(T), \operatorname{Pl}(T)]$.

In calculating three importance indexes, as there are epistemic uncertainties in the system, the node $E_{i}(1 \leq$ $i \leq n)$ has three statuses, that is, $E_{i}=1, E_{i}=0$, and $E_{i}=\{0,1\}$. Except for structural importance, the computation processes of the other two indexes are both containing interval numbers. Let $P(\cdot)$ be the average of $\operatorname{Bel}(\cdot)$ and $\mathrm{Pl}(\cdot)$, that is,

$$
P(\cdot)=\frac{(\operatorname{Bel}(\cdot)+\mathrm{Pl}(\cdot))}{2} .
$$

Then the three importance indexes are obtained by (5) (7).

The three importance indexes are able to find the most important risks in logistics financial business. However, the indexes are unable to show how much uncertainty in root node is produced by each bottom event. Therefore, a new importance index, called "epistemic importance" in this paper, is defined to meet this requirement. Denote the occurrence probability of a risk $X_{i}$ to be $\left[\inf \left(p_{i}\right), \sup \left(p_{i}\right)\right](i=$ $1,2, \ldots, n)$, and the probability of the root node to be $\left[\mathrm{Bel}_{c}, \mathrm{Pl}_{c}\right]$ when there are epistemic uncertainties in logistics financial business. Let the occurrence probability of the risk $X_{i}$ be a constant, mid $\left(p_{i}\right)$, and calculate the probability of root node, $\left[\mathrm{Bel}_{i}, \mathrm{Pl}_{i}\right]$, on this occasion. Then the epistemic importance of $X_{i}$ is defined as

$$
I_{i}^{\mathrm{ep}}=\frac{\left(u_{c}-u_{i}\right)}{u_{c}},
$$

where

$$
u_{c}=\mathrm{Pl}_{c}-\mathrm{Bel}_{c}, \quad u_{i}=\mathrm{Pl}_{i}-\mathrm{Bel}_{i} \text {. }
$$




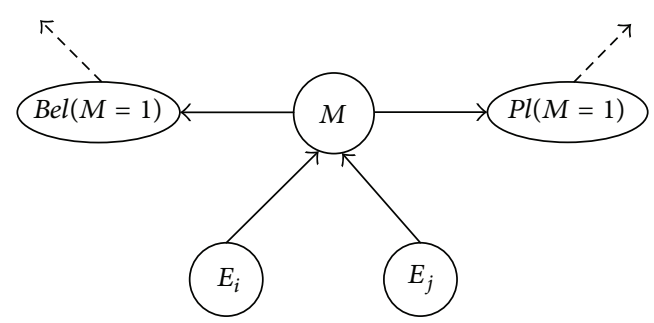

Figure 2: Probability model of intermediate node in evidential network.

TABLE 4: Calculating method for belief and plausibility measures of intermediate node.

\begin{tabular}{lcc}
\hline Status of $M$ & $\operatorname{Bel}(M=1)$ & $\operatorname{Pl}(M=1)$ \\
\hline 0 & 0 & 0 \\
1 & 1 & 1 \\
$0 \_1$ & 0 & 1 \\
\hline
\end{tabular}

Epistemic uncertainty is caused by the lack of information and knowledge. The more the information is, the little the epistemic uncertainty is. If there is enough information, epistemic uncertainty may disappear. So the epistemic importance index could give a direction of collecting more data on important risks so that to get a more accurate value of the occurrence probability of logistics financial business.

\section{Numerical Examples}

With sufficient market survey and considering the experts' opinions, the occurrence probability of each risk is obtained by combing these information using Dempster's rule, which is shown in Table 5.

The failure probability of logistics financial business is calculated by (4) as 0.1192 . Three importance indexes are shown in Table 6.

From Table 6, all of the three indexes agree that $X_{6}, X_{7}, X_{10}, X_{11}, X_{14}$, and $X_{15}$ are the least important risks. That is to say, the risks of malicious falsehood of finance enterprise, malicious cheating of insiders, no corresponding laws to support the logistics finance agreement, comprehension rifts in contract for three main bodies, uninsured pledges, and deteriorations in pledges are all not primary factors to the failure of logistics financial business. So in risk analysis and decision making, all these factors can be ignored. The other risks have almost identical values of probabilistic importance. It means that these risks are all important factors for logistics financial business, and should be paid enough attention to avoid their occurrences.

If there are epistemic uncertainties in the occurrence probabilities of the risks, as shown in Table 7, then the failure probability of logistics financial business is obtained as $[0.0839,0.1397]$. The three importance indexes and epistemic importance are calculated and shown in Table 8.

As can be seen in Table 8 , the orders of uncertainty and epistemic importance of each risk are not the same. Uncertainty in each risk could not reflect its importance to
TABLE 5: Occurrence probabilities of risks.

\begin{tabular}{lc}
\hline Risk & Probability \\
\hline$X_{1}$ & 0.0001 \\
$X_{2}$ & 0.0001 \\
$X_{3}$ & 0.01 \\
$X_{4}$ & 0.01 \\
$X_{5}$ & 0.02 \\
$X_{6}$ & 0.01 \\
$X_{7}$ & 0.0005 \\
$X_{8}$ & 0.005 \\
$X_{9}$ & 0.005 \\
$X_{10}$ & 0.02 \\
$X_{11}$ & 0.01 \\
$X_{12}$ & 0.01 \\
$X_{13}$ & 0.01 \\
$X_{14}$ & 0.02 \\
$X_{15}$ & 0.04 \\
$X_{16}$ & 0.01 \\
$X_{17}$ & 0.01 \\
$X_{18}$ & 0.01 \\
$X_{19}$ & 0.01 \\
$X_{20}$ & 0.01 \\
$X_{21}$ & 0.05 \\
\hline
\end{tabular}

the root node. For example, uncertainties in $X_{10}$ and $X_{14}$ are very large, while their epistemic importance indexes are very small; uncertainty in $X_{5}$ is smaller than $X_{10}$ and $X_{14}$, but its epistemic importance is the largest within all risks. Although the orders of probabilistic importance and epistemic importance are almost the same; however, in the first 14 risks in Table 8 , the values of probabilistic importance are roughly equal, while, in epistemic importance, $X_{5}$ is considerably larger than the others. In qualitative analysis, the first 14 risks have almost the same values on probabilistic importance, which show that they have almost the same impacts to the occurrence of the root node. But the uncertainties in $X_{5}$ are obviously larger than the other 13 . Synthesizing these two factors aforementioned, epistemic importance of $X_{5}$ is larger than the others. The qualitative results are consistent with the quantitative results and reflect the objective facts.

Through the above analysis we can draw conclusions: to reduce the failure probability of logistics financial business, management should be focused on the first 14 risks in Table 8; to get a more accurate result of failure probability of the business, more investigation should be done on $X_{5}$ to get more information to reduce the uncertainties in it.

\section{Conclusions}

There are three sources of risks coming from bank, finance enterprise, and 3PL in logistics financial business. These risks may lead to the failure of the business. In this paper, the risks in the business are identified and classified, and a Bayesian network is constructed to analyze the risks in the logistics finance. To handle the epistemic uncertainties in 
TABLE 6: Three importance indexes.

\begin{tabular}{lccc}
\hline Risk & $I_{i}^{\mathrm{Pr}}$ & $I_{i}^{\mathrm{St}} \times 10^{-5}$ & $I_{i}^{\mathrm{Cr}} \times 10^{-3}$ \\
\hline$X_{5}$ & 0.8988 & 2.57 & 150.78 \\
$X_{20}$ & 0.8897 & 2.57 & 74.63 \\
$X_{19}$ & 0.8897 & 2.57 & 74.62 \\
$X_{18}$ & 0.8897 & 2.57 & 74.62 \\
$X_{17}$ & 0.8897 & 2.57 & 74.62 \\
$X_{16}$ & 0.8897 & 2.57 & 74.62 \\
$X_{13}$ & 0.8897 & 2.57 & 74.62 \\
$X_{12}$ & 0.8897 & 2.57 & 74.62 \\
$X_{4}$ & 0.8897 & 2.57 & 74.62 \\
$X_{3}$ & 0.8897 & 2.57 & 74.62 \\
$X_{21}$ & 0.8852 & 2.57 & 37.12 \\
$X_{9}$ & 0.8852 & 2.57 & 37.12 \\
$X_{8}$ & 0.8852 & 2.57 & 37.12 \\
$X_{2}$ & 0.8809 & 2.57 & 0.73 \\
$X_{1}$ & 0.8809 & 2.57 & 0.73 \\
$X_{14}$ & 0.0353 & 0.85 & 5.91 \\
$X_{15}$ & 0.0176 & 0.85 & 5.91 \\
$X_{11}$ & 0.0176 & 0.85 & 1.47 \\
$X_{10}$ & 0.0088 & 0.858 & 1.47 \\
$X_{7}$ & 0.0088 & 0.858 & 0.36 \\
$X_{6}$ & 0.0044 & 0.858 & 0.36 \\
\hline & & &
\end{tabular}

TABLE 7: Occurrence probabilities of risks in epistemic uncertain system.

\begin{tabular}{lc}
\hline Risk & Probability \\
\hline$X_{1}$ & {$[0.0001,0.0002]$} \\
$X_{2}$ & {$[0.0001,0.0002]$} \\
$X_{3}$ & {$[0.008,0.012]$} \\
$X_{4}$ & {$[0.008,0.012]$} \\
$X_{5}$ & {$[0.01,0.03]$} \\
$X_{6}$ & {$[0.004,0.016]$} \\
$X_{7}$ & {$[0.004,0.006]$} \\
$X_{8}$ & {$[0.004,0.006]$} \\
$X_{9}$ & {$[0.004,0.006]$} \\
$X_{10}$ & {$[0.01,0.04]$} \\
$X_{11}$ & {$[0.008,0.012]$} \\
$X_{12}$ & {$[0.008,0.012]$} \\
$X_{13}$ & {$[0.008,0.012]$} \\
$X_{14}$ & {$[0.01,0.04]$} \\
$X_{15}$ & {$[0.04,0.06]$} \\
$X_{16}$ & {$[0.008,0.012]$} \\
$X_{17}$ & {$[0.008,0.012]$} \\
$X_{18}$ & {$[0.008,0.012]$} \\
$X_{19}$ & {$[0.008,0.012]$} \\
$X_{20}$ & {$[0.008,0.012]$} \\
$X_{21}$ & {$[0.04,0.06]$} \\
\hline
\end{tabular}

the business, evidence theory is used in conjunction with Bayesian network to construct an evidential network, and a new definition of epistemic importance index is proposed
TABLE 8: Importance indexes for epistemic uncertain system.

\begin{tabular}{lccccc}
\hline Risk & Uncertainty & $I_{i}^{\mathrm{Pr}}$ & $I_{i}^{\mathrm{St}} \times 10^{-5}$ & $I_{i}^{\mathrm{Cr}} \times 10^{-3}$ & $I_{i}^{\mathrm{Ep}}$ \\
\hline$X_{5}$ & 0.02 & 0.8869 & 2.575 & 190.45 & 0.3309 \\
$X_{20}$ & 0.004 & 0.8707 & 2.575 & 74.79 & 0.0701 \\
$X_{18}$ & 0.004 & 0.8707 & 2.575 & 74.79 & 0.0701 \\
$X_{17}$ & 0.004 & 0.8707 & 2.575 & 74.79 & 0.0701 \\
$X_{16}$ & 0.004 & 0.8707 & 2.575 & 74.79 & 0.0701 \\
$X_{13}$ & 0.004 & 0.8707 & 2.575 & 74.79 & 0.0701 \\
$X_{12}$ & 0.004 & 0.8707 & 2.575 & 74.79 & 0.0701 \\
$X_{4}$ & 0.004 & 0.8707 & 2.575 & 74.79 & 0.0701 \\
$X_{3}$ & 0.004 & 0.8707 & 2.575 & 74.79 & 0.0701 \\
$X_{21}$ & 0.002 & 0.8654 & 2.575 & 37.17 & 0.0701 \\
$X_{9}$ & 0.002 & 0.8654 & 2.575 & 37.17 & 0.0382 \\
$X_{8}$ & 0.002 & 0.8654 & 2.575 & 37.17 & 0.0382 \\
$X_{19}$ & 0.004 & 0.8613 & 2.575 & 7.39 & 0.0079 \\
$X_{2}$ & 0.0001 & 0.8604 & 2.575 & 1.23 & 0.0079 \\
$X_{1}$ & 0.0001 & 0.8604 & 2.575 & 1.23187 & 0.0079 \\
$X_{14}$ & 0.03 & 0.0690 & 8.58 & 19.76 & 0.0297 \\
$X_{15}$ & 0.02 & 0.0345 & 8.58 & 19.76 & 0.0385 \\
$X_{11}$ & 0.004 & 0.0344 & 8.58 & 2.95 & 0.0107 \\
$X_{10}$ & 0.03 & 0.0137 & 8.58 & 0.59 & 0.0117 \\
$X_{7}$ & 0.002 & 0.0103 & 8.58 & 2.95 & 0.0001 \\
$X_{6}$ & 0.012 & 0.00516229 & 8.58 & 0.59 & 0.0001 \\
\hline & & & & &
\end{tabular}

to express the impact of epistemic uncertainties in each risk to the entire business. The numerical examples show that the proposed method can find the most important risk in the business and give a quantitative measure of the failure of the business. The new index, epistemic importance, can discover the impact of epistemic uncertainties in each risk to the epistemic uncertainties in logistics financial business. With the abovementioned information, targeted and effective approaches can be found to control and avoid these sensitive risks, thus keep logistics financial business working more reliable. The proposed method also gives a quantitative value of risks in logistics financial business, which provides guidance for the selecting of financing solutions.

\section{Acknowledgments}

This work was supported by the Scientific Research Foundation of Southwest University of Science and Technology under Grant no. 12sx7106.

\section{References}

[1] E. Jokivuolle and S. Peura, "Incorporating collateral value uncertainty in loss given default estimates and loan-to-value ratios," European Financial Management, vol. 9, no. 3, pp. 299314, 2003.

[2] J. A. Buzacott and R. Q. Zhang, "Inventory management with asset-based financing," Management Science, vol. 50, no. 9, pp. 1274-1292, 2004. 
[3] W. Jia and B. Chen, "Financial risk, business risk and firm value for logistics industry," in Proceedings of the 4th International Conference on Wireless Communications, Networking and Mobile Computing (WiCOM '08), pp. 1-4, October 2008.

[4] D. Cossin, Z. J. Huang, and D. Aunon-Nerin, A Framework for Collateral Risk Control Determination, European Central Bank Working Paper Series, 2003.

[5] R. Rajan and A. Winton, "Covenants and collateral as incentives to monitor," The Journal of Finance, vol. 50, no. 4, pp. 1113-1146, 1995.

[6] B. F. Chen, G. Z. Feng, and Y. X. Li, "The value risk measurement of inventory financing," Systems Engineering, vol. 25, no. 10, pp. 21-26, 2007.

[7] W. Chang, H. Q. Hu, and D. H. Zhang, "Liquidity risk measurement of inventory financing," Forecasting, vol. 28, no. 6, pp. 7175, 2009.

[8] J. Coulter and G. Onumah, "The role of warehouse receipt systems in enhanced commdity marketing a rural livelihoods in Africa," Food Policy, vol. 27, no. 4, pp. 319-337, 2002.

[9] Y. Yan, H. Ye, and B. Shuai, "Decision-making of two financing businesses using evidence theory," Journal of Convergence Information Technology, vol. 7, no. 1, pp. 222-229, 2012.

[10] L. Zhou, J. Jiang, and B. Liu, "The research on modes and application of inventory financing," Advances in Intelligent and Soft Computing, vol. 137, pp. 35-42, 2012.

[11] S. D. Grimshaw and W. P. Alexander, "Markov chain models for delinquency: transition matrix estimation and forecasting," Applied Stochastic Models in Business and Industry, vol. 27, no. 3, pp. 267-279, 2011.

[12] S. B. Bai and H. Liu, "A study of the risk-return in contracted enterprises with confirming storage financing," Soft Science, vol. 23, no. 10, pp. 118-122, 2009.

[13] O. Doguc and J. E. Ramirez-Marquez, "A generic method for estimating system reliability using Bayesian networks," Reliability Engineering and System Safety, vol. 94, no. 2, pp. 542550, 2009.

[14] D. Marquez, M. Neil, and N. Fenton, "Improved reliability modeling using Bayesian networks and dynamic discretization," Reliability Engineering and System Safety, vol. 95, no. 4, pp. 412425, 2010 .

[15] M. Lampis and J. D. Andrews, "Bayesian beliefnetworks for systemfault diagnostics," Quality and Reliability Engineering International, vol. 25, no. 4, pp. 409-426, 2009.

[16] J. Li, J. Shi, and D. Satz, "Modeling and analysis of disease and risk factors through learning Bayesian networks from observational data," Quality and Reliability Engineering International, vol. 24, no. 3, pp. 291-302, 2008.

[17] Y. W. Zhang, T. Y. Chai, and Z. M. Li, "Modelling and monitoring of dynamic processes," IEEE Transactions on Neural Networks and Learning System, vol. 23, no. 2, pp. 277-284, 2012.

[18] Y. Zhang, H. Zhou, S. J. Qin, and T. Chai, "Decentralized fault diagnosis of large-scale processes using multiblock kernel partial least squares," IEEE Transactions on Industrial Informatics, vol. 6, no. 1, pp. 3-10, 2010.

[19] M. K. Carl and H. David, MSBNx: A Component-Centric Toolkit for Modeling and Inference with Bayesian Networks, Microsoft Corporation, Seattle, Wash, USA, 2001.

[20] H. Boudali and J. B. Dugan, "A continuous-time Bayesian network reliability modeling, and analysis framework," IEEE Transactions on Reliability, vol. 55, no. 1, pp. 86-97, 2006.
[21] A. P. Dempster, "Upper and lower probabilities induced by a multivalued mapping," Annals of Mathematical Statistics, vol. 38, pp. 325-339, 1967.

[22] G. Shafer, A Mathematical Theory of Evidence, Princeton University Press, Princeton, NJ, USA, 1976.

[23] P. Limbourg and E. de Rocquigny, "Uncertainty analysis using evidence theory-confronting level-1 and level-2 approaches with data availability and computational constraints," Reliability Engineering and System Safety, vol. 95, no. 5, pp. 550-564, 2010. 


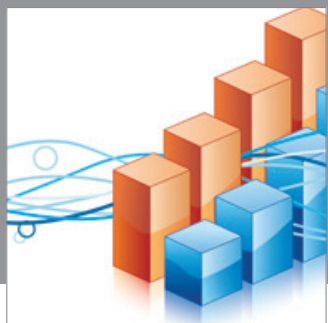

Advances in

Operations Research

mansans

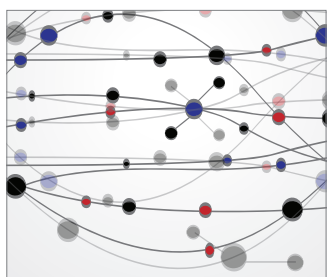

The Scientific World Journal
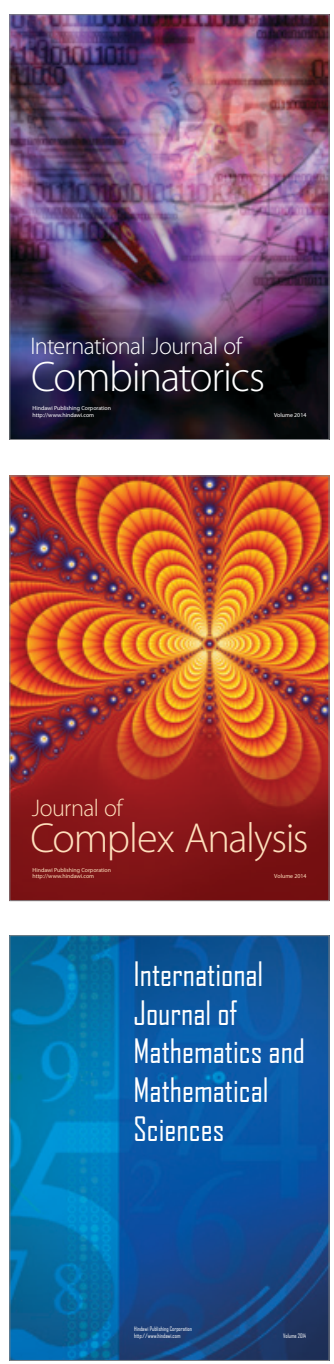
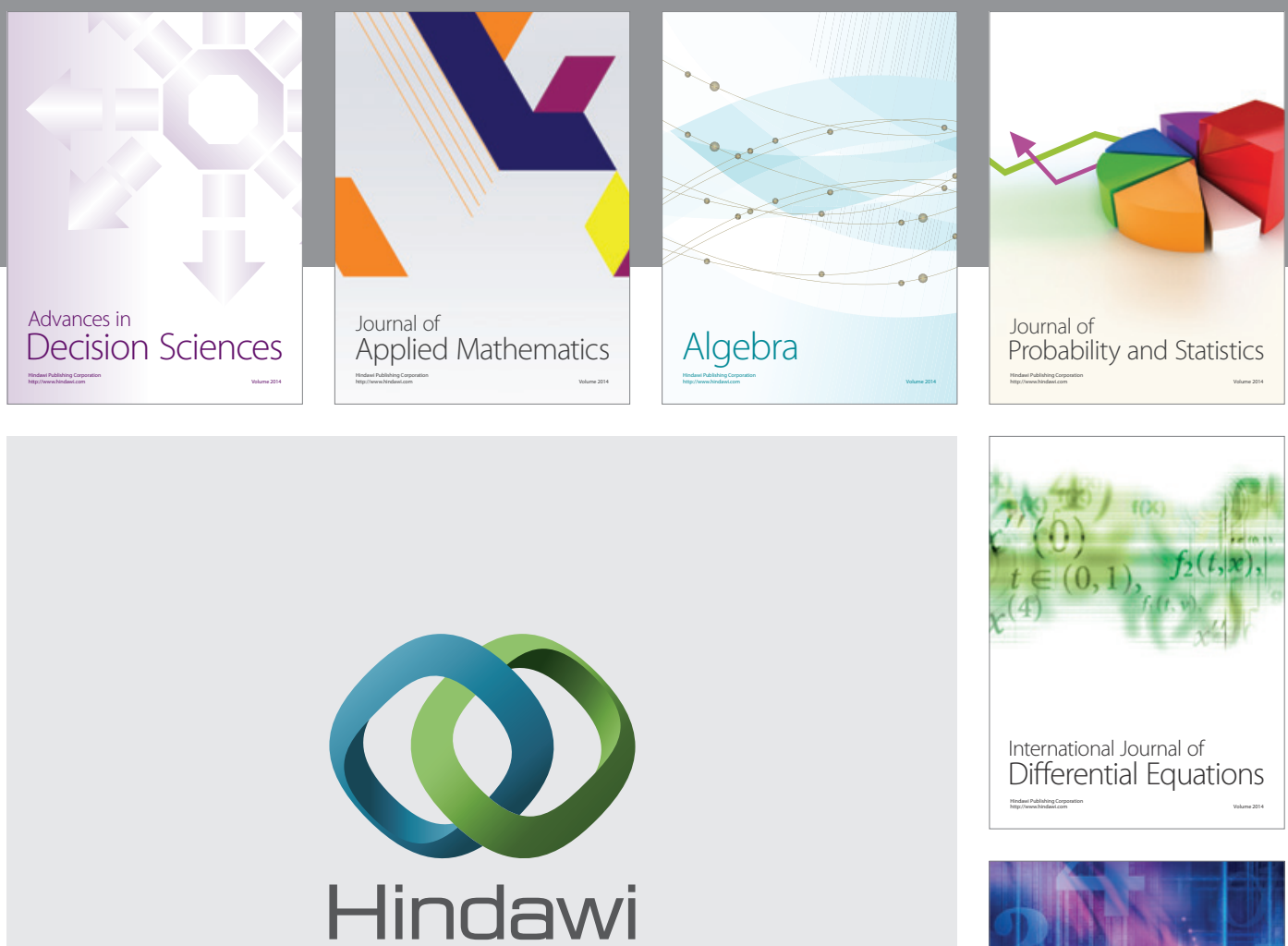

Submit your manuscripts at http://www.hindawi.com
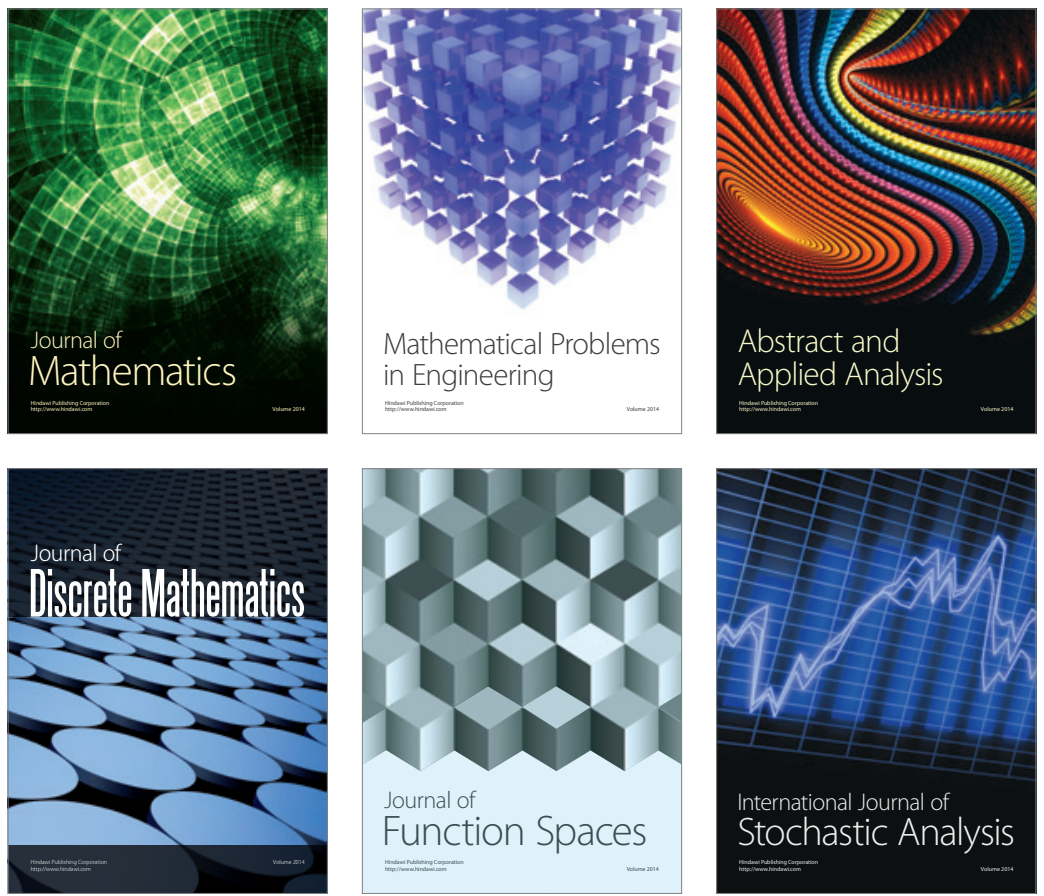

Journal of

Function Spaces

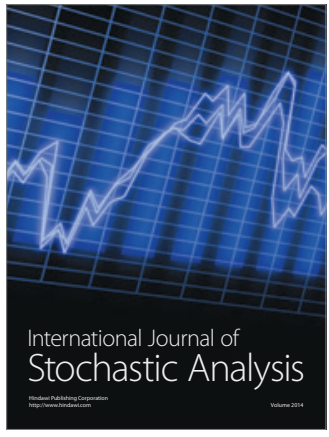

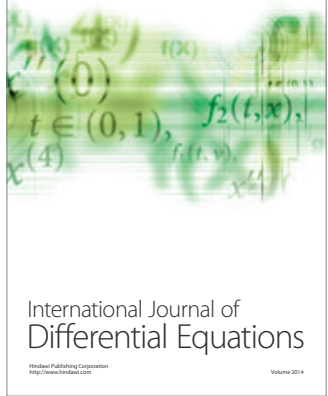
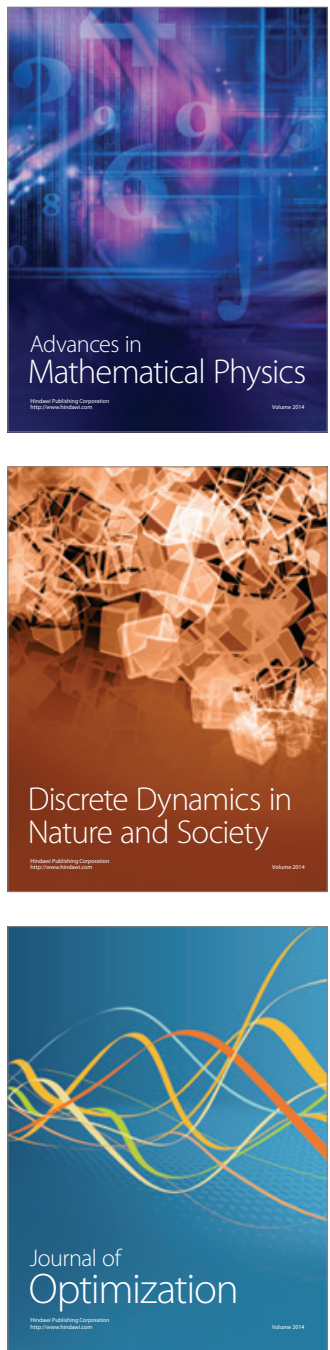